\title{
La culpa la tiene Hipatia
}

\author{
Elena Soledad Jiménez Ayala \\ Departamento de Matemática Aplicada y Estadística, \\ Universidad Politécnica de Cartagena, \\ C/ Dr. Fleming s/n (Campus Muralla del Mar), \\ e-mail: elena.jimenez@upct.es \\ Presentado en eXIDO18 (2018)
}

\section{RESUMEN}

Vivimos en una sociedad donde las ciencias están en todo lo que nos rodea, particularmente las Matemáticas. Sin embargo, cuando entramos en las aulas nos encontramos ante situaciones que nos pueden resultar un tanto comprometidas o incluso, muy complicadas de resolver. El "para qué debo estudiar ecuaciones si no las voy a usar nunca" es una barrera a veces muy difícil de superar. Esto, como profesores, nos plantea el siguiente reto: inculcar el gusto por las ciencias, y en este caso, por las Matemáticas. Ello debe hacerse desde edades muy tempranas, y en particular, que las descubran por si mismos suele ser la mejor estrategia. Así pues, a lo largo de este trabajo se verán métodos que nos han resultado útiles para alcanzar nuestro objetivo. A través de películas como Hipatia de Alejandria o Dentro del Laberinto, se presentaran conceptos como: el cono de Apolonio, cónicas o grafos. Estos trabajos han sido realizados tanto por alumnos de secundaria, en este caso de $2^{\circ}$ de la ESO, como por profesores de secundaria de diferentes materias, ya que, por experiencia, sabemos que lo interdisciplinar funciona mejor. Como resultado obtuvimos un aumento en las solicitudes de alumnos en las ramas de ciencias y una visión de las Matemáticas más amplia por parte del profesorado involucrado.

Palabras clave: Interdisciplinar, cono de Apolonio, cónicas, grafos, Hipatia de Alejandría, Geocentrismo, Heliocentrismo, laberinto, backtracking.

\section{Objetivos}

- Acercar al alumnado y al profesorado a la investigación científica dentro y fuera del aula.

- Proporcionar herramientas para comenzar y continuar haciendo este tipo de proyectos.

- Motivar en la búsqueda de apariciones, aplicaciones e implicaciones de las Matemáticas en la realidad que nos rodea. 
- Presentar, a modo de ejemplo, varios de los trabajos realizados por alumnos de $2^{\circ}$ de la ESO (IES Juan Sebastián Elcano e IES Isaac Peral de Cartagena) donde las Matemáticas conectan con la realidad.

\section{Contenidos}

Los contenidos que se desarrollarán a lo largo de este artículo son:

1. La investigación científica: qué significa investigar, pasos a seguir en una investigación científica.

2. Investigando con alumnos de la ESO: pasos a seguir.

3. Trabajos de investigación elaborados con alumnos:

- IES Juan Sebastián Elcano: "Hipatia, filósofa y maestra"; "Centrum"; "Instrumentos matemáticos. El cono de Apolonio".

o IES Isaac Peral: "Dentro del Laberinto".

4. Conclusiones.

5. Agradecimientos.

\section{La investigación científica. ¿Qué significa investigar?}

La investigación es un proceso que, mediante la aplicación del método científico, procura obtener información relevante y fidedigna (digna de fe y crédito), para entender, verificar, corregir o aplicar el conocimiento.

En nuestro caso, la investigación científica consiste en la búsqueda intencionada de conocimientos o de soluciones a problemas de carácter científico y tiene como base el método científico. Éste es fundamental para el estudiante y para el profesor, puesto que ayuda a mejorar el estudio y además permite establecer contacto con la realidad, de manera que podamos conocerla mejor.

Su finalidad es:

- Formular nuevas teorías o modificar las existentes.

- Incrementar los conocimientos.

- Llegar a elaborar nuevas teorías.

Es importante tener en cuenta que un ambiente favorable puede estimular al investigador en los momentos de desánimo. El clima científico, el ambiente de trabajo, con frecuencia, suplen con creces otras carencias.

\section{Pasos a seguir en una investigación científica}

1. Elegir el tema.

2. Plantear los objetivos que se quieren alcanzar.

3. Delimitar el tema.

4. Plantear el problema a tratar. 
5. Investigar el marco teórico.

6. Determinar la metodología a seguir.

7. Elaborar el informe final con los resultados obtenidos.

\section{Investigando con alumnos de la ESO.}

El problema, en la mayoría de los casos, surge cuando se desea realizar una investigación con alumnos de la ESO, para ello es muy importante que, aunque sea el profesor el que les guíe hacia un tema, sean ellos los que finalmente decidan sobre qué quieren aprender, teniendo en cuenta sus posibilidades para abordarlo y el tiempo que van a poder dedicarle y, sobre todo, que disfruten haciéndolo, ya que de lo contrario será un fracaso.

\section{Pasos a seguir con el alumnado}

- Elegir y delimitar el tema: Como hemos comentando al empezar este apartado, debe ser un tema que el alumnado tenga ganas de abordar. Si no se les ocurre nada, puede buscar en bibliotecas, Internet, preguntando a los amigos o al profesor que les va a dirigir el proyecto... Otra idea, es hacer una tormenta de ideas entre los que van a formar un mismo grupo y ver qué sale. $Y$ por último $e$ importantísimo, delimitar el tema, si no se hace corremos el riesgo de que se desanimen porque no vean fin al trabajo a investigar.

- Planificar los pasos: Primero hay que pensar en los objetivos a alcanzar, para ello es bueno hacerse un guión con los pasos que se van a seguir. Para hacer un buen plan es bueno que el alumno o grupo pida ayuda a la persona que se lo va a dirigir. El plan debe de estar abierto a los posibles imprevistos que puedan surgir. Es bueno que este plan se revise de vez en cuando para ver si se están cumpliendo los objetivos que se tenían programados.

- Diagrama: Una vez elegido el tema es bueno hacer un diagrama con los posibles subtemas relacionados con la idea a investigar, y anotar aquellas preguntas de las que se quiera buscar una respuesta.

- Antecedentes: Se deben revisar aquellos conceptos y conocimientos previos que ya conocen sobre el tema y ver de qué se quiere aprender más.

- Fuentes de información: Hay que valorar cuáles son las principales, entre ellas encontramos las bibliotecas, los libros de texto, Internet... Es bueno no quedarse con lo primero que se encuentre, hay que buscar y contrastar la información obtenida a través de las diferentes fuentes. 
- Selección de los documentos: Una vez se tienen todos los documentos, es necesario hacer una selección de cuáles pueden servir y cuáles no, desechando los no válidos. Se debe de apuntar el autor y procedencia de los documentos seleccionados para así poder citarlos luego en el trabajo.

- Completar el diagrama: Una vez seleccionada la información se debe elaborar un guión del trabajo, rellenando el diagrama que se hizo anteriormente y contestando a aquellas preguntas que surgieron al principio. Será imprescindible que haya un orden claro y que esté bien estructurado, ya que supone el esqueleto del trabajo a investigar.

- Elaboración de informe: Primero se ha de decidir de qué manera se va a presentar el trabajo, si es a través de un artículo, de un póster científico, de una exposición oral... puesto que, según el caso, se debe presentar el trabajo con una estructura $u$ otra. Es importantísimo que la presentación de este informe, sea clara, ordenada, concisa y limpia.

\section{Trabajos de investigación elaborados con alumnos.}

\section{IES Juan Sebastián Elcano.}

Las ideas surgieron tras el visionado de la película "Ágora" de Alejandro Amenábar, y el grupo elegido fue $2^{\circ}$ de la ESO. Un grupo con unas características óptimas para este tipo de trabajo, formado por alumnos académicamente normales, pero muy activos.

En un comienzo se les propusieron varios temas después de ver con ellos la película y de hacerles una serie de preguntas sobre ella, con idea de ver si realmente habían atendido y comprendido lo que habían visto. Pero estos no terminaron de convencerles. Así que se planteó hacer una brainstorm, es decir, una tormenta de ideas. Fue entonces cuando surgieron varios temas como: el por qué del movimiento de los planetas, qué era el cono de Apolonio, las Matemáticas y la moda, quién era Hipatía de Alejandría en la realidad... Así que reagrupamos a los alumnos según los temas que más les interesaban.

El resultado del trabajo fue bueno en los tres casos, si bien, para lograr que fuesen constantes en su trabajo en algunos casos fue difícil, llegando en algún caso a abandonar, dado que se dieron cuenta que el tema no les interesaba de verdad. Otros sin embargo disfrutaron muchísimo y al terminar comenzaron a pensar, por su cuenta, en qué tipo de proyectos nuevos se querían embarcar.

Véanse uno a uno los tres proyectos y la utilidad que tuvieron para relacionar las Matemáticas con la realidad y para fomentar la curiosidad científica. 


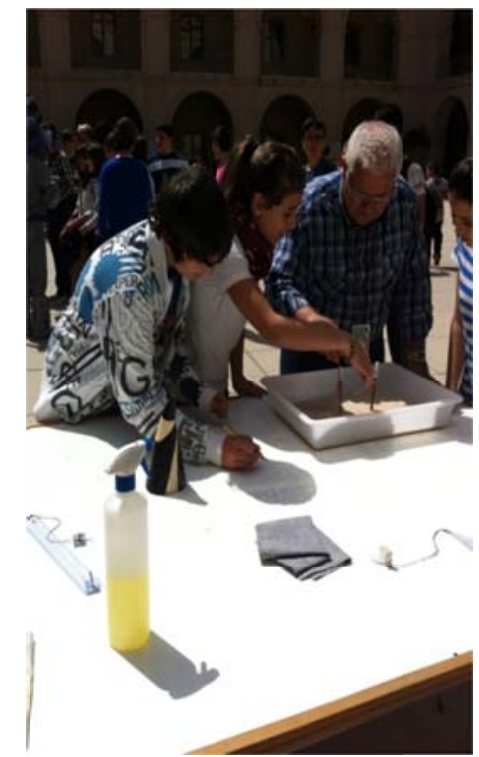

Alumnos de la ESO enseñando a profesores universitarios las cónicas

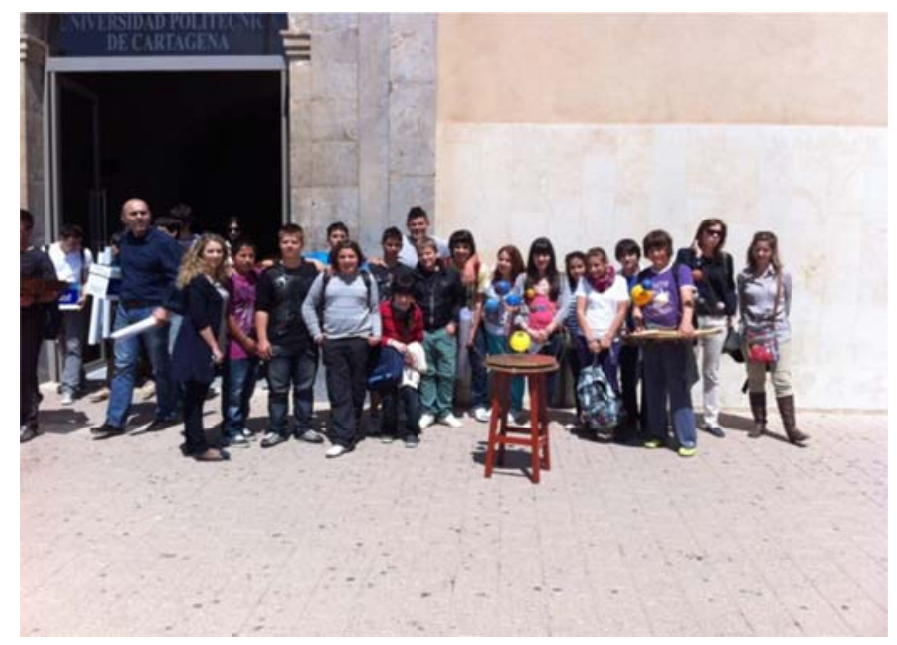

Algunos alumnos y profesores que participaron en los proyectos

\section{Hipatia, filósofa y maestra}

Este trabajo fue el punto de partida de los otros dos. En él se introduce la figura de Hipatia, su vida y obra, un recorrido a través del arte: Pintura, Literatura y Cine. Por último, se hace un breve comentario sobre la Biblioteca de Alejandría. 


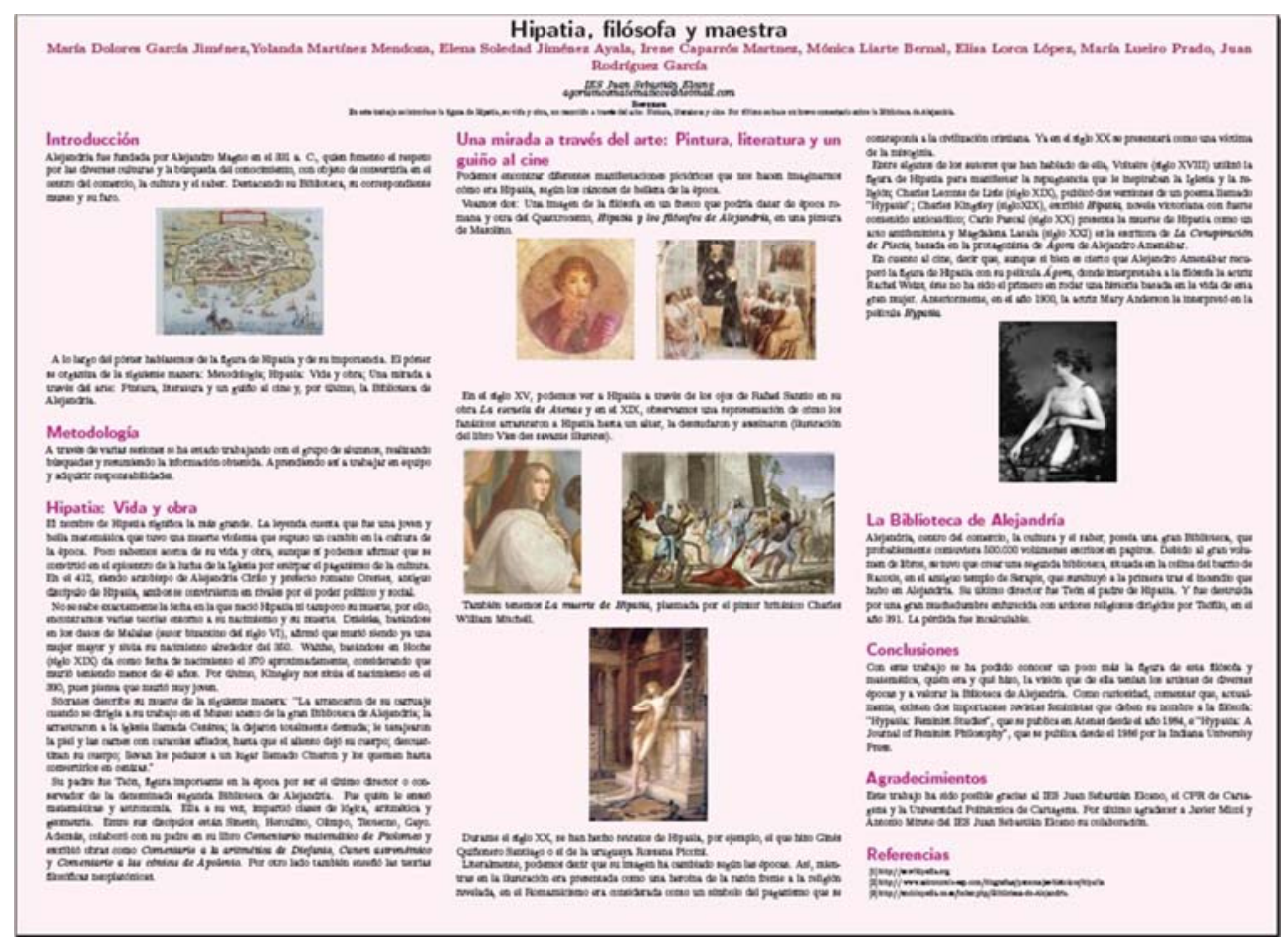

¿Qué hemos conseguido con él?

- Aprender un poco de la historia de las Matemáticas.

Saber que existieron en la Antigüedad mujeres que, en época de hombres, no solo las estudiaban, sino que también las enseñaban.

- La aparición e importancia de la Matemáticas a través del arte. Han aprendido como, según las distintas épocas, Hipatia de Alejandría es representada de una manera o de otra.

- La influencia en la literatura.

A lo largo de los siglos han sido múltiples las teorías acerca de su muerte, ha sido utilizada como imagen del feminismo... Por otro lado, no solo se han escrito libros relacionados con Hipatia, sino que hay revistas que actualmente llevan su nombre.

- La influencia en el cine.

No solo en el cine actual, como ocurre con la película "Ágora", sino también en películas más antigüas como "Hypatia", del año 1900, donde la actriz Mary Anderson la interpretaba.

- Por último, ha sido la excusa perfecta para que aprendan un poco más sobre la Biblioteca de Alejandría y la importancia que tuvo.

\section{Centrum}




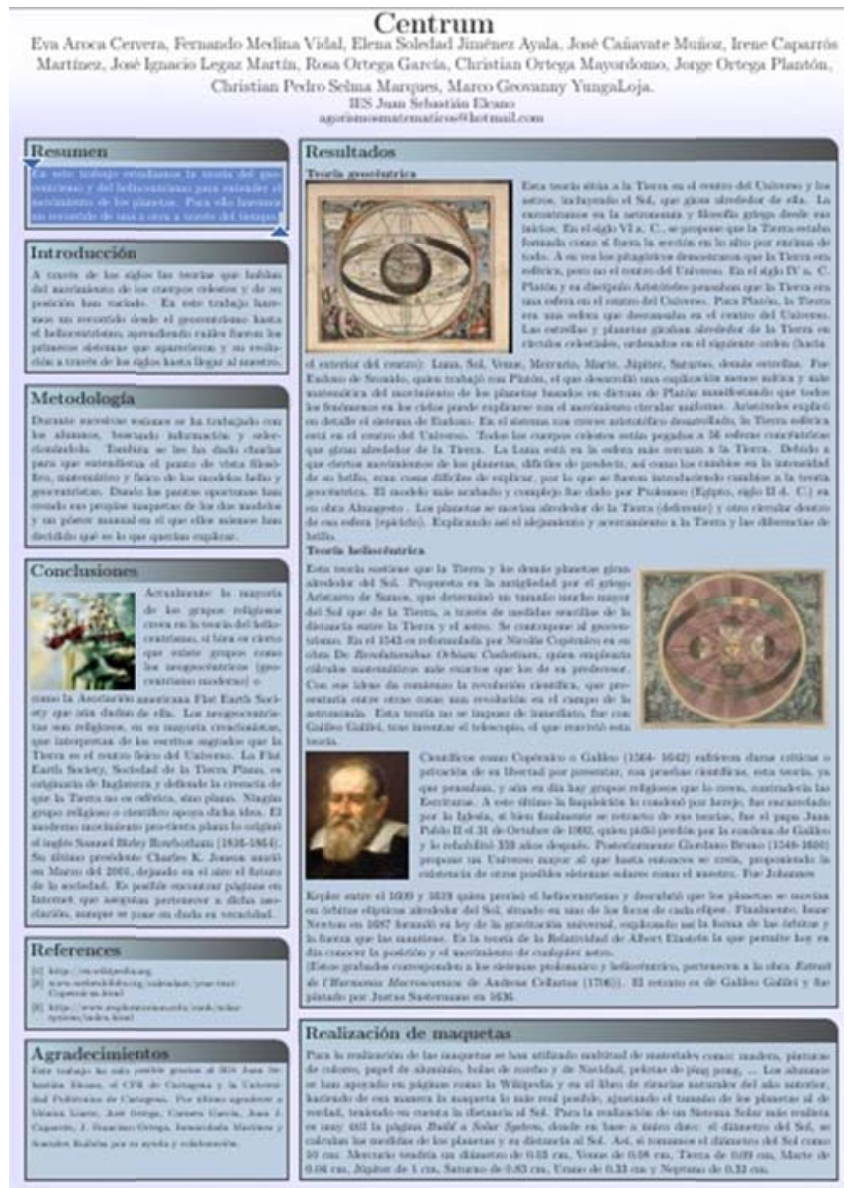

Una de las obsesiones con las que se nos presenta a Hipatia es la del movimiento de los planetas. Se deduce que los planetas no giraban describiendo circunferencias y alrededor de la Tierra, como en el modelo antiguo de Ptolomeo, sino que describían órbitas elípticas.

En este trabajo se estudió la teoría del geocentrismo y del heliocentrismo para entender el movimiento de los planetas. Para ello, se hizo un recorrido de una a otra a través del tiempo.

¿Qué hemos conseguido con él?

- Dar a conocer parte de la historia de las Matemáticas y de la Astronomía. Saber quiénes eran Pitágoras, los pitagóricos, Aristóteles, Ptolomeo, Nicolás Copérnico, Galileo Galilei... Sus pensamientos y teorías.

- Conocer más a fondo las teorías del Geocentrismo y del Heliocentrismo.

- Hablar de la revolución científica, viendo hasta qué punto fue importante la aportación de las Matemáticas en las ideas de Copérnico, ideas que dieron comienzo a esta revolución.

- Introducir a los alumnos dos de los tipos más importantes de cónicas que existen como son la circunferencia y la elipse. 
Matemáticas y Educación

- La construcción por parte de los alumnos de maquetas de los dos sistemas estudiados: geocentrismo y heliocentrismo (pueden verse abajo las dos imágenes respectivamente).

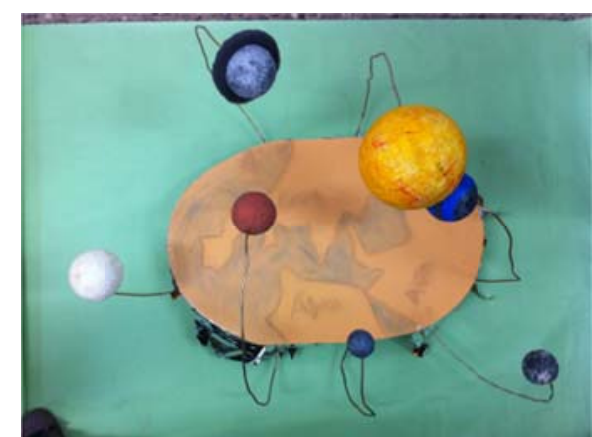

Sistema Geocéntrico.

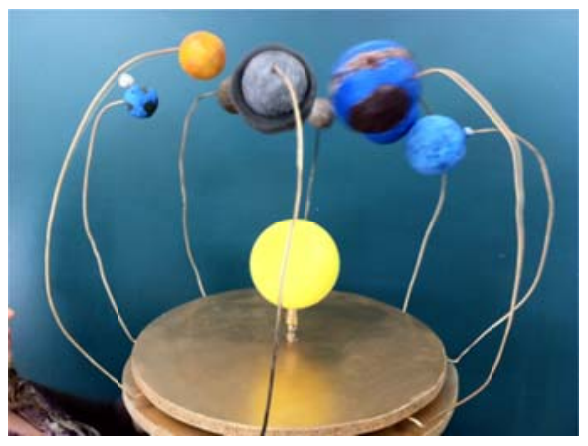

Sistema Heliocéntrico. 
Matemáticas y Educación



Una vez que se había decidido el segundo trabajo, este tercero lo completaba a la perfección. Surgió la duda de si había alguna cónica más y se decidió a través del cono de Apolonio describir cuatro de las más importantes: circunferencia, elipse, parábola e hipérbola.

Como al principio les costaba entender algunas de ellas y con el propósito de que aprendiesen que se las pueden encontrar por todas partes, se les propuso, tras enseñarles algunos ejemplos sacados de Internet, el buscarlas en los objetos cotidianos y realizar fotos. Algunas de las imágenes son las siguientes.

- Circunferencias:
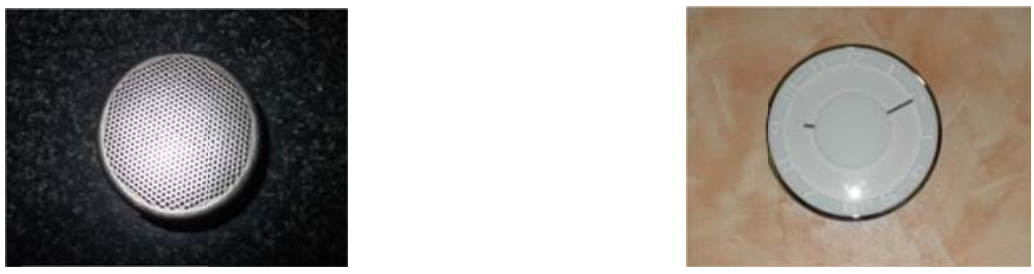

- Elipses:
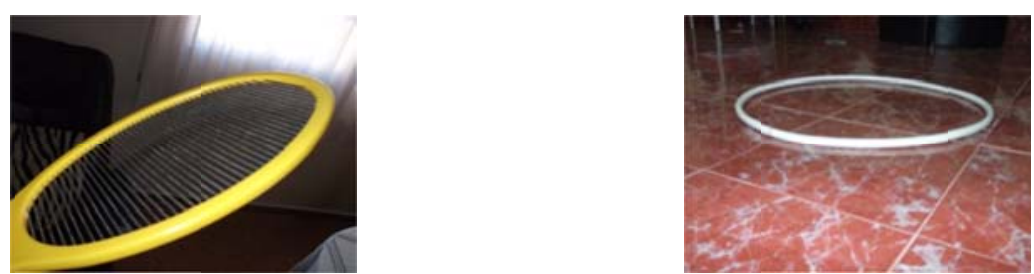
Una vez conocidas las cónicas, se procedió a buscar la manera de dibujarlas, para ello tuvieron que conocer las partes más importantes de ellas y sus propiedades. Posteriormente utilizando regla, compás, una cuerda, ventosas, arena... aprendieron a dibujarlas.

Pero quizá lo más interesante de este trabajo fue la pregunta que surgió a la hora de construir el cono de Apolonio: "Seño, ¿y cómo hacemos para dar los cortes?". Aprendieron que según uno corte el cono con un plano u otro la cónica que sale es distinta y que al final salían las cuatro que ya habían estudiado.

Vemos algunas imágenes del cono construido por ellos y las cónicas que obtuvieron al realizar los cortes:

- Cono de Apolonio:

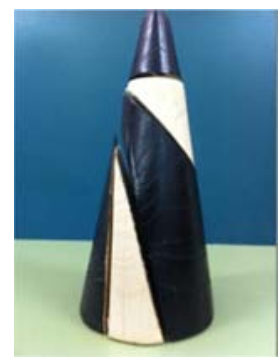

- De izquierda a derecha: circunferencia, elipse, parábola e hipérbola:



¿Qué hemos conseguido con él?

- Conocer parte de la historia de las Matemáticas. Quién era Apolonio y qué importancia tuvieron él y su cono.

- Aprender cuatro de las cónicas más importantes: circunferencia, elipse, parábola e hipérbola.

- Observar que dichas curvas se encuentran en nuestra vida cotidiana a través de la fotografía.

- Saber dibujarlas y conocer sus características más importantes.

- Conocer algunos instrumentos más de la época de Hipatia de Alejandría. 


\section{IES Isaac Peral.}

\section{Dentro del laberinto}

Las ideas surgieron tras el visionado de la película "Dentro del Laberinto" de Jim Henson (1986) y el grupo elegido fue $2^{\circ}$ de la ESO. De nuevo un grupo con unas características óptimas para este tipo de trabajo, formado por alumnos académicamente normales, pero muy activos. Alumnos con los que ya se había trabajado en otro tipo de actividades y que de forma voluntaria se ofrecieron a trabajar en ello.

En este caso una vez realizado el visionado de la película, se propusieron una serie de actividades de profundización.

Ejemplo de actividades:

Actividad Busca qué parte de las Matemáticas estudia la Topologia.

Clasificación de laberintos:

A laberintos que no contienen circuitos cerrados, tales como el faberinto que se muestra en el siguiente dibujo:

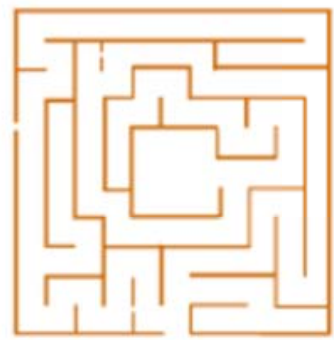

los topólogos los llaman "simplemente conectados". Esto equivale a decir que el laberinto no tiene muros separados.

Los laberintos con muros separados si contienen circuitos cerrados, y se les conoce como laberintos de "conexiones múltiples"; un ejemplo es el siguiente laberinto.

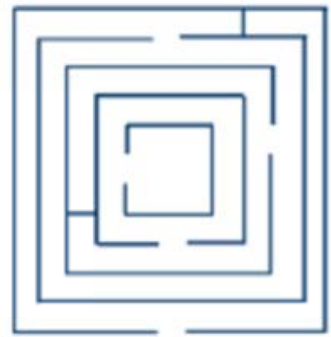

Actividad: Según la clasificación que hemos dado a los distintos tipos de laberintos, ¿qué tipo de laberinto es el que encontramos en la pelicula?

Actividad: Busca otras dos peliculas, donde aparezcan laberintos. Clasificalos.

Tras ellas se les planteó el tema directamente. La idea por parte del profesorado era que, acorde a su nivel, aprendiesen su historia, así como su vinculación con la literatura y el mundo de las ideas y de los símbolos. E introducir de una manera más o menos llamativa y encubierta los métodos de 
resolución de laberintos, así como la teoría de grafos. Todo ello, claro está, de una forma amena y divertida.

Una vez terminadas las actividades propuestas para el aula, los profesores involucrados, se reunieron en sucesivas ocasiones para elaborar todo el contenido a trabajar por parte del alumnado. De esta manera se estudiaron los orígenes de los laberintos y su tipología. Los métodos de resolución: método de la mano derecha (recorrer la pared y cada vez que haya un cruce girar a la derecha) y búsqueda en profundidad (algoritmo que permite recorrer todos los nodos de un grafo o árbol, de manera ordenada, pero no uniforme).

Como conclusión del trabajo realizado, dos años más tarde hubo un aumento en el número de matrículas en ciencias en el instituto, y los mismos alumnos, tanto de letras como de ciencias participaron de nuevo en otro proyecto del cual hablaremos en otra ocasión.

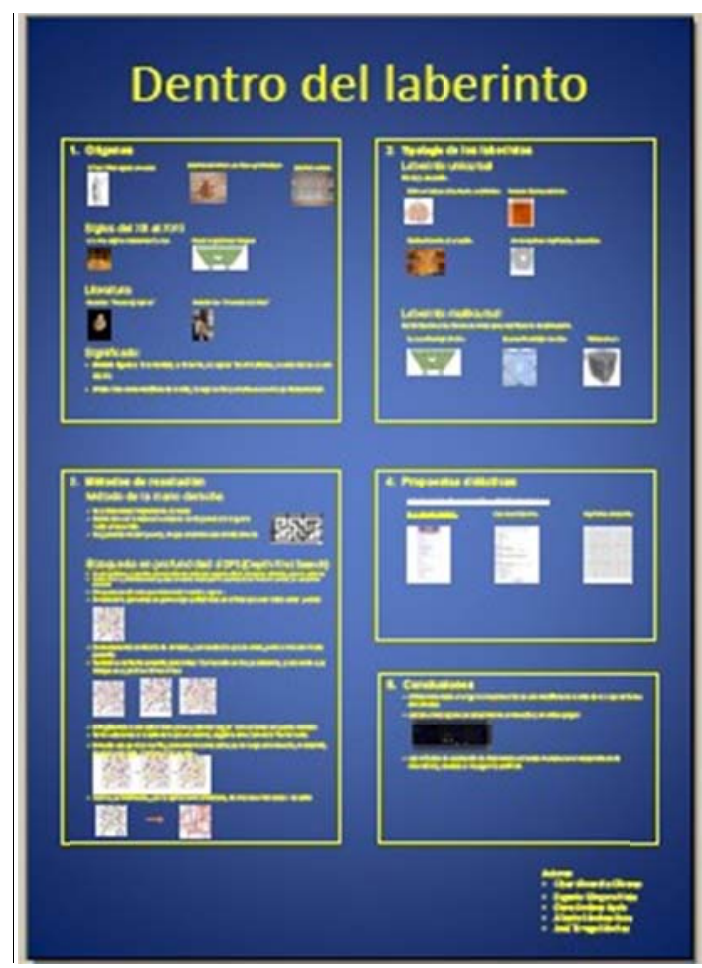

¿Qué hemos conseguido con él?

- Conocer parte de la historia de estas construcciones, así como otro tipo de significado de la propia palabra laberinto: "metáfora de la vida, la superación y el esfuerzo como eje fundamental".

- Aprender las distintas tipologías básicas y ser capaces de clasificarlos en unicursales (clásico, romano, medieval y contemporáneo) y multicursales (de conexión simple, de conexión múltiple y tridimensionales).

- Descubrir dos de los principales métodos de resolución: método de la mano derecha y búsqueda en profundidad (DFS).

- Crear grafos a partir de la búsqueda en profundidad. 
- Utilizar un programa de generador de laberintos y crear así los suyos propios.

- Saber que los laberintos no solo aparecen novelas y en video juegos sino que los métodos de resolución de laberintos son fundamentales en el desarrollo de la informática, robótica e inteligencia artificial.

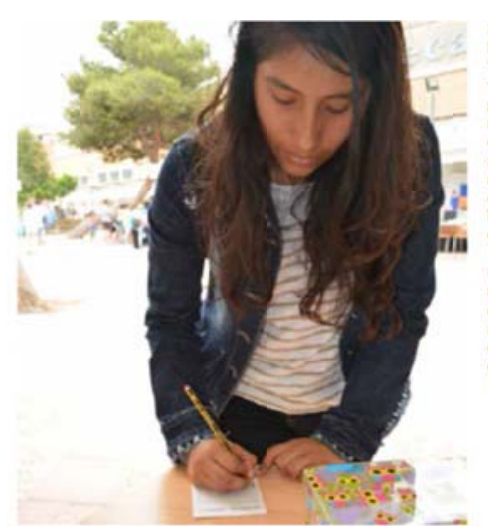

Alumna resolviendo un laberinto en papel

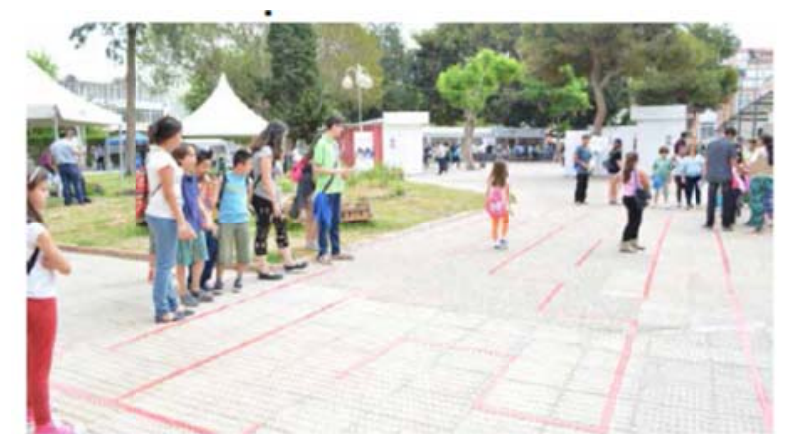

Alumnos resolviendo un laberinto en pleno campus de la ingeniería (UPCT)

\section{Conclusiones.}

Es muy importante motivar al alumnado para que aprecie que las Matemáticas forman parte de nuestra vida cotidiana, que no son solo un ente abstracto que no sirve nada más que para sumar restar y poco más. Para ello se propone usar la investigación científica y realizar proyectos en el aula. Es tarea del profesor transmitir el amor hacia ellas y buscar la manera de transmitirlo.

Como reflexión:

Si no mostramos entusiasmo por las Matemáticas, difícilmente podremos transmitirlo.

\section{Agradecimientos.}

Consejería de Educación de Murcia, en particular al CPR y a la Universidad Politécnica de Cartagena.

También agradecer a los profesores del IES Juan Sebastián Elcano: María Dolores García Jiménez, Yolanda Martínez Mendoza, María Dolores Conesa Nieto, José Díaz García, Eva Aroca Cervera y Fernando Medina Vidal. Y del IES Isaac Peral: César Almarcha Olivares, Eugenio Góngora Nieto, Alberto Sánchez-Roca y José Tárraga Sánchez. Por su paciencia y trabajo al frente con los alumnos y porque sin ellos no hubiera podido llevar a cabo dichos proyectos.

Por último y con todo mi cariño a los alumnos de $2^{\circ}$ de la ESO, ya que son ellos los principales protagonistas de todo esto. Gracias, por enseñarme tanto. 


\section{REFERENCIAS}

\section{Bibliografía}

1. Molina Vargas, Jason; Torres Pinzón, Carlos; Restrepo Patiño, Carlos (2008). Técnicas de Inteligencia Artificial para la solución de laberintos de estructura desconocida. Scientia et Technica Año XIV, No 39.

2. Redal, Enrique Juan et al (2010). Matemáticas I. España, Ed Santillana.

3. Hernández Fernández, Isabel; Mateos Contreras, Consuelo; Núñez Valdés, Juan. (2010). ¿Perderse en un laberinto? No con las matemáticas.

Unión, Revista Iberoamericana de Educación

Matemática, No 21. Pág. 69-85.

\section{Webgrafía}

1. http://anagarciaazcarate.wordpress.com/2013/08/20/encuentra-la-salida-ellaberinto-de-areas/

2. http://www.astronomia-esp.com/biografias/personajes-histoicos/hipatia.

3. http://dibujotecnico09.blogspot.com.es/2010/02/las-conicas-el-cono-deapolonio.html

4. http://ecured.cu/index.php/Laberinto.

5. http:// enciclopedia.us.es/index.php/Biblioteca-de-Alejandría.

6. http://es.wikipedia.org

7. http://www.exploratorium.edu/ronh/solar-system/index.html

8. http://www.it.uc3m.es/jvillena/irc/practicas/06-07/09.pdf

9. http://www.labyrinthos.net.

10. http://maze.askdefine.com/

11. http://pequenoldn.librodenotas.com/matiaventuras/1374/un-laberinto-con-19salas

12. http://puzzlemaker.discoveryeducation.com/AdvMazeSetupForm.asp

13. http://www.webexhibits.org/calendars/year-text-Copernicus.html 